\title{
El vanguardismo eterno: el principio dialógico en la novela española e hispanoamericana
}

Palabras clave: vanguardia, novela polifónica, autoficción, narradores españoles e hispanoamericanos

DOI: 10.4312/ars.11.2.155-167

\section{Marco teórico: de la mirada monológica a la mirada polifónica}

Ya desde el inicio del siglo XX vivimos las épocas agónicas y confusas en la historia de la novela. El arte en general y la novela en particular del siglo XIX se han beneficiado de la capacidad de representar la realidad, de contar historias. Por esta razón la narratividad se ha convertido en el rasgo estético principal del arte decimonónico. Se reflexionó sobre los límites del arte y se fue formando una nueva poética que adoptó el nombre de vanguardista. Con el arranque de las vanguardias se abandonó la representación mimética como principio estético y se atribuyó a la forma autonomía respecto a su referencia: «El futurismo poético o el cubismo pictórico quisieron vehicular una poética y una estética que arrancara a los materiales de su servidumbre referencial y dotara a la palabra o el cuadro de un valor en sí mismo, por lo que los materiales y los volúmenes adquirieron fuerza propia» (Pozuelo Yvancos, 2004, 21).

Las primeras manifestaciones de crisis finisecular decimonónico (por ejemplo, la poética modernista o el impresionismo) se manifiestan pues en la pérdida de la narratividad y en el agotamiento de la estética mimético-representativa, lo que conduce el arte hacia una metamorfosis particular hoy llamada estética de la vanguardia. El mundo imaginativo de las acciones se sustituyó por el invisible mundo psicológico de los estados del alma, por el mundo de las ideas, por las formas. Ortega y Gasset lo explica así:

Nuestro interés - dice- se ha transformado, de la trama a las figuras, de los actos a las personas. Ahora bien -y vaya dicho esto como un intermedioeste desplazamiento coincide con el que en la ciencia física y sobre todo en la filosófica, se inicia desde hace veinte años. Desde Kant a 1900 predomina una exacerbada tendencia a eliminar de las teorías las sustancias por las formas... ¿Por ventura tornamos hoy de las acciones a la persona y de la función a la sustancia? (Ortega y Gasset, 1969, 171-172) 
Las vanguardias renovaron no solo el contenido y la forma del arte, sino que cuestionaron el concepto mismo de expresión artística. El arte se aparta de lo real prácticamente hasta los límites posibles, aunque no puede prescindir por completo de referencias a la realidad, "desde la teoría y la realización formal, en la vida práctica» (Pozuelo Yvancos, 2004, 39). En ese proceso de alejamiento se cuestiona el mismo horizonte estético, lo que no ha ocurrido durante el realismo decimonónico. Ortega y Gasset escribe el texto filosófico La deshumanización del arte (1925) sobre el nuevo arte de hacer arte en el que considera como sinónimos los conceptos la desrealización y la deshumanización partiendo de las vanguardias pictóricas, pero refiriéndose también a la literatura, sobre todo a la poesía ${ }^{1}$ :

El expresionismo, el cubismo, etc. han sido en varia medida intentos de verificar esta resolución en la dirección radical del arte (el irrealismo). De pintar las cosas se ha pasado a pintar las ideas: el artista se ha cegado para el mundo exterior y ha vuelto la pupila hacia los paisajes internos y subjetivos (Ortega y Gasset, 1987, 79).

¿Qué influencia ha tenido la estética vanguardista sobre la novela? Decididamente la deshumanización del arte ha sido también la respuesta que se ha manifestado en la novela, de cuya agonía o muerte próxima se discutía ya desde el final del siglo XIX. La novela que se basaba en la narratividad no pudo sobrevivir sin cambios, tuvo que seguir la deformación de la realidad y responder con conceptos radicalmente distintos del realismo. El viejo arte de narrar historias de modo lineal se rompió como modelo, los núcleos conceptuales de la novela cambiaron; por eso había que recoger los pedazos de la narración y recomponerlos de manera nueva, distinta, presentativa. Como advierte Mihaíl Bajtin en su estudio sobre la poética de Dostoievski, se fue creando una nueva estética del arte, un nuevo concepto de forma artística; consecuentemente en la teoría de la novela se formó un nuevo discurso llamado dialógico, es decir, la novela dejó de ser monológica para convertirse en polifónica:

La creación de la novela polifónica es para nosotros un enorme paso adelante no sólo en el desarrollo de la prosa novelesca, esto es, de todos los géneros que se desarrollan en la órbita de la novela, sino en general en el desarrollo del pensamiento artístico de la humanidad. Nos parece que se puede hablar directamente acerca del pensamiento artístico polifónico que traspasa los límites del género novelesco. Este tipo de pensamiento es capaz de alcanzar tales aspectos del hombre -ante todo la conciencia pensante del hombre y la esfera dialógica de su existencia- que no son abarcables artísticamente desde una posición monológica (Bajtin, 1986, 395).

1 Sus ideas impactaron mucho a los jóvenes poetas españoles de la Generación de 1927. 
La polifonía de la novela presupone la quiebra de la referencialidad narrativa; y justamente ese proceso de romper la relación entre lo narrado y su referencia, su fuente, representa el núcleo artístico de la estética vanguardista ${ }^{2}$. Por esa razón la focalización en la novela se trasladó desde la posición autor-narrador hacia autor-personaje. Ese paso decisivo propone un nuevo relieve del personaje que debe revolucionar el lenguaje narrativo hacia un nuevo discurso múltiple, pluralizado:

El héroe de Dostoievski no es sólo la palabra acerca de sí mismo y de su entorno más próximo, sino también la palabra acerca del mundo; el héroe no es solamente un ser consciente, sino un ideólogo. [...] Por eso la palabra acerca del mundo se confunde con el discurso confesional sobre sí mismo. La verdad sobre el mundo, según Dostoievski, es inseparable de la verdad personal. [...] De este modo se logra la fusión artística, tan típica de Dostoievski, entre la vida personal y la visión del mundo, entre la vivencia más íntima y la idea. La vida personal se vuelve singularmente desinteresada en los principios ideológicos, y el pensamiento ideológico superior se hace íntimamente personal y apasionado (Bajtin, 1986, 116-117).

Bajtin destaca la ruptura del artificio de la realidad definida, cerrada en las novelas monológicas realistas para alzar la polifonía de voces narrativas en la nueva novela polifónica. El nuevo autor vierte todos sus pensamientos no definidos, borrosos, en status nascens en sus personajes que orquestan la polifonía narrativa; el mundo complejo de los personajes, tanto exterior como interior, igualmente como el mundo del autor se convierte en la misma fuente de significación. Las técnicas formales más explícitas, orientadas hacia la autonomía de la voz del personaje, son por ejemplo el monólogo interior o el flujo de la conciencia:

A Dostoievski no le importa qué es lo que el héroe representa en el mundo sino, ante todo, qué es lo que representa el mundo para él y qué es lo que viene a ser para sí mismo.

Éste es un punto muy importante y fundamental de la percepción del héroe. El héroe como punto de vista, como mirada sobre el mundo y sobre sí mismo requiere métodos muy especiales de representación y caracterización (Bajtin, 1986, 73-74).

Y en este punto cambia también el papel del lector que tiene que despertarse de su comodidad receptora y activarse en el proceso creador. Con la nueva novela la recepción se convierte en el discurso dialógico entre el autor y el lector, se trata de un intercambio entre dos sujetos. «El arte debe ser como ese espejo / que nos revela nuestra propia cara», precisa Jorge Luis Borges en su conocido poema Arte poética $(2002,60)$. Cada lector ha de encontrar su espejo, su reflexión, debe captar un punto de 
vista del autor o una de sus miradas que «puede invitar, cautivar, liberar, pero también hechizar, engañar y matar, puede ser directa o estar oculta, puede ser omnipotente o prohibida, múltiple o impotente» (Šabec, 2015, 9).

\subsection{La revolución cervantina}

En su novedad narrativa de carácter revolucionario la novela vanguardista revive el discurso dialógico y otorga la misma importancia esencial al personaje como se la dio Cervantes en el Quijote. En esta primera novela moderna su autor ofrece al lector la pluralidad de narradores, la independencia de sus ideas, una narración más discursiva que referencial. A pesar de que hace entrar la realidad en la novela (sobre todo con los elementos de la novela picaresca), también muestra que la realidad es múltiple desde las ideas que el héroe las lleva y con las que la interpreta. Cervantes nos enseñó la ambigüedad de la realidad que permite múltiples sentidos e interpretaciones. El autorpersonaje es consciente de la necesidad de ficción para poder interpretar la realidad, que no es solo realista sino también filosófica, irónica, ilusionante, fictiva. En su novela el mundo realista se enfrenta al mundo idealista con un claro anhelo de síntesis. Por eso la nueva novela, tanto la de Cervantes como la de la estética vanguardista, debe ser una muestra de tensiones entre el mundo ideal y el mundo real: «La tensión del Quijote promete no gastarse nunca» (Ortega y Gasset, 2004, 299).

El Quijote abre las puertas a los mundos cerrados de la novela anterior, rompe las fronteras narrativas, presenta la complejidad de ideas y siembra el desconcierto interpretativo. Cervantes le transmite al lector su propio diálogo existencial que mantiene con el héroe: «Para mí sola nació don Quijote, y yo para él: él supo obrar y yo escribir, solos los dos somos para en uno» (Cervantes, II, LXXIV, 2004, 1105). Cervantes le concede al lector la conciencia de su individualismo, le transmite el protagonismo, lo obliga a opinar para que construya su propia realidad, su propio reino hecho de realidad e invención, de credulidad y locura; de este modo el lector puede aportar inacabables interpretaciones.

\section{Hacia la actualidad}

\subsection{La vanguardia}

La vanguardia del inicio del siglo XX ha encontrado desde su propia revolución estética concordancia con la novela de Cervantes. Porque no se trata únicamente de la teoría estética sino de síntesis, de fusión entre la irrealidad artística y la determinada forma de vivir y de ver el mundo. La vanguardia, igualmente como el arte de Cervantes, tiene intención de influir sobre la realidad, de romper con los 
viejos conceptos, de abrir espacios cerrados y de entablar batalla y amistad, es decir, un diálogo complejo.

Aunque la estética vanguardista fue muy destructiva e intolerante hacia las corrientes artísticas del pasado -su mirada se orientaba exclusivamente hacia el futuro celebrando los progresos de la nueva sociedad industrial y magnificando casi como nuevos mitos todos los aspectos del arte moderno- su concepto estético radicalmente nuevo abrió en la humanidad la puerta al optimismo: el artista podía intervenir de modo significativo en la sociedad para sanar las heridas de la realidad circundante, la estética adquirió cierta ambición revolucionaria. De este modo se inició la metamorfosis artística: en la novela se desarrolló la novela polifónica que supuso un nuevo paradigma dialógico donde el sujeto se encuentra con el otro. Se trata de:

un quiebro definitivo en la tesitura de la constitución de los discursos sociales, $\mathrm{y}$, por ende, uno de los conceptos que permitirían un lenguaje no sujeto al poder divino, monológico y autoritario de narrador-autor, sino sometido a ser plurilingüístico, un magma donde desembocan los decires, los hablares de los personajes y de las conciencias ... (Pozuelo Yvancos, 2004, 40).

\subsection{Los autores españoles e hispanoamericanos}

Entre los autores españoles que entendieron la novedad narrativa como oportunidad de renovación, volviendo también la mirada hacia el concepto cervantino de la novela, fue Miguel de Unamuno con la novela, llamada nivola, que recurre al método dialógico ${ }^{3}$. Su mejor realización es también su más conocida novela, Niebla (1914), que entre otras novedades revitaliza la confusión entre la realidad y la ficción de Cervantes, y borra de nuevo la frontera entre la ilusión y la realidad: "Y hay que confundir. Confundir sobre todo, confundirlo todo. Confundir el sueño con la vela, la ficción con la realidad, lo verdadero con lo falso; confundirlo todo en una sola niebla» (Unamuno, 1995, 146).

La revolución modernista-vanguardista tuvo aun más impacto sobre la literatura hispanoamericana. Efectivamente el modernismo y luego la vanguardia suponen la independencia de la literatura hispanoamericana, que plenamente desarrolla su propio contexto literario desde el inicio del siglo XX. Pero la ruptura con la literatura española al mismo tiempo significa el comienzo de una nueva etapa de diálogo, de colaboración, de influencias y de corrientes comunes. En el paradigma polifónico de la nueva novela

3 A causa de la oposición académica a las novedades conceptuales en la novela, Unamuno inventó el nuevo nombre calificando su novela como nivola, pudiendo ser también definida como un nuevo género. Las novedades introducidas por Unamuno en el campo novelesco son por ejemplo la confusión realidad-ficción, la estrategia narrativa del «manuscrito encontrado», el diálogo con el propio personaje, la novela dentro de la novela, el perspectivismo, etc., todas ya son conocidas en el Quijote. 
el diálogo se dispara en diferentes direcciones: la narrativa hispanoamericana (cuento y novela) mágicorrealista, fantástica, irreal influye sobre los autores de todo el mundo. Además, la corriente mágicorrealista no hubiera nacido sin el movimiento surrealista de André Breton y su teoría surrealista basada en las investigaciones psicoanalíticas de Sigmund Freud. La narrativa hispanoamericana, una vez independizada de la vigilancia artística española, establece el diálogo filosófico y estético con el mundo occidental al que le devuelve en el siglo XX grandes textos narrativos que se inscribirán en la historia de la novela.

\subsection{El posmodernismo}

Con la llegada de Jorge Luis Borges sobre el escenario literario podemos hablar del inicio del posmodernismo ${ }^{4}$. La estética vanguardista desde su posición metahistórica destruyó el pasado, lo anuló y con su glorificación del mundo de las ideas y de lo abstracto llegó al final de un callejón sin salida. Como considera Umberto Eco en las Apostillas a El nombre de la rosa: «Pero llega el momento en que lo moderno consiste en reconocer que, puesto que el pasado no puede destruirse -su destrucción conduce al silencio-, lo que hay que hacer es volver a visitarlo, con ironía, sin ingenuidad» (Eco, 1984, 74). El ámbito de lo posmoderno se genera una vez presente la imposibilidad de seguir con la perpetua novedad vanguardista. Escribe John Barth en su ensayo The Literature of Exhaustion (1967) que la estética modernista está en desgaste, que se ha llegado al final del camino vanguardista, por eso hay que redefinir el concepto de novela. Barth cree en las artes híbridas y sugiere a los autores que redescubran lo tradicional (los artificios del lenguaje y del argumento) añadiendo los elementos del arte contemporáneo. Como ejemplo ideal de la literatura posmoderna presenta la prosa de Borges, que pone en duda la idea misma de la representación de la realidad. Sus ficciones siempre hacen dudar a sus lectores sobre qué es original y qué es copia, qué es realidad y qué su reduplicación ilusoria en el espejo. La realidad borgeana no tiene una sola interpretación, no es posible entenderla solo de una manera. En su profundidad sus ficciones siguen el mismo procedimiento dialógico con la realidad exterior que fue abierto por la estética vanguardista. Al mundo, según Borges, le hace falta la ficción porque consiste de un conjunto de laberintos, de tiempos y espacios paralelos, de textos y sus palimpsestos, cada texto literario contiene huellas de textos anteriores; escribir para él significa reescribir porque todo texto conserva rastros de una escritura anterior ${ }^{5}$. Su literatura es la glorificación de la literatura misma que no pretende ser nada más que la literatura pero cuyos límites se esparcen en la realidad y por eso cambian su percepción.

4 Borges empezó su carrera literaria con la poesía ultraísta. El ultraísmo fue uno de los -ismos de la poética vanguardista.

5 El término griego palimpsestos significa palin- «de nuevo» y psestós- «raspado». 
Desgraciadamente la literatura posmodernista -también la novela- de finales del siglo XX y del inicio del XXI ha entrado (otra vez) en crisis. Como es sabido el contexto epistémico posmodernista se encuentra en su incesante proceso de polifonía, de diálogo, de mutabilidad. Todo se permite, todo se puede mezclar, todo es posible, nada es seguro. La novela posmodernista ha vivido la multiplicación de mensajes sin normas estéticas dominantes porque el posmodernismo implica la simultaneidad de distintos discursos que no se excluyen entre sí, sino que se complementan; el sistema de nuevas relaciones y de nuevas interpretaciones ofrece nuevos contextos y perspectivas. Y en el escenario narrativo de polifonía, de heteroglosia de mensajes, de caos informativo y estético aparece la pluralidad de tendencias como única constante.

El posestructuralismo refuerza el concepto de originalidad al límite de la insignificancia. En este ámbito en el que la novela se ha convertido en un producto más de estrategias de marketing y de la industria cultural los escritores se plantean dos preguntas esenciales: ¿cómo determinar su relación con el pasado? y ¿cómo encontrar y luego expresar su propia originalidad sin perder su identidad? La novela posmoderna tiene que reflejar en cierto modo las dudas existenciales de la realidad y al mismo tiempo mantener el diálogo con el pasado, con la historia, por eso se convierte en adaptación, comentario, interpretación, crítica, homenaje, imitación, parodia.

Tanto la novela hispanoamericana como la novela española han caído en la fungibilidad literaria (Pozuelo Yvancos, 2004, 48) del mecanismo mercantil global. La novela hispanoamericana ${ }^{6}$ del final del siglo XX y del inicio del XXI ha perdido su identidad común latinoamericana, los narradores siguen las tendencias globales narrando sobre su identidad personal. Se ha disuelto la metáfora de Macondo (Gabriel García Márquez ${ }^{7}$ y ha sido reemplazada por la de McOndo. En 1996 Alberto Fuguet y Sergio Gómez en el manifiesto Presentación del país McOndo terminan con la tradición novelesca de la identidad latinoamericana (sobre todo ponen fin al realismo mágico) para incorporarla a la corriente literaria global que se basa en la búsqueda individualista y minuciosa y forma parte de la cultura instantánea, repetible, de la cultura del mundo McDonald's.

La novela española también se ha incorporado a las tendencias globales, se ha sometido a las exigencias de la poderosa industria editorial y asimismo se ha expuesto

6 Término común que utiliza la crítica literaria sobre todo desde la perspectiva europea, aunque se trata de narrativas procedentes de diferentes países hispanoamericanos.

7 Gabriel García Márquez escribió la gran novela del siglo XX Cien años de soledad en la que determinó el mundo mágicorrealista llamado Macondo. Esta novela tuvo enorme impacto sobre el modo de narrar de muchos autores por el mundo; el autor mezcló los tiempos, los espacios, las técnicas narrativas y los géneros. También en muchas novelas posteriores García Márquez practicó las mismas técnicas narrativas. Por ejemplo, en la Crónica de una muerte anunciada: «Márquez rompió con las reglas del género mencionado [la novela policial], no solo debido a su argumento sino también por lo que hizo con su manera de narrar» (Fock, 2010, 199). 
a las transformaciones estéticas exigidas por el mercado. En el comercio literario han aparecido muchos escritores nuevos, apoyados por editoriales económicamente potentes a las que únicamente les importaba el prestigio y el éxito financiero. Muchos narradores españoles de finales del siglo pasado empezaron a preguntarse sobre los valores literarios de la novela, sobre cómo establecer el diálogo con la realidad, sobre su propio papel creador de la ficción, como también sobre el proceso de la recepción de la literatura:

A comienzos del siglo XXI, como si mis pasos llevaran el ritmo de la historia más reciente de la literatura, me encontré solitario y sin rumbo en una carretera perdida, al atardecer, en marcha inexorable hacia la melancolía. [...] En el arte me veía rodeado de odiosas mentiras, falsificaciones, mascaradas, fraudes por todas partes. Y además me sentía muy solo. Y cuando miraba lo que tenía frente a mis ojos veía siempre lo mismo: la literatura a comienzos del siglo XXI, agonizando (Vila-Matas, 2002, 245).

Se han reciclado las preguntas esenciales sobre los límites de la literariedad que había propuesto Cervantes hace más de cuatro siglos sin que se hayan encontrado respuestas claras o unificadoras. Ha surgido otra vez la pregunta sobre la crisis de la novela, esta vez dentro de la perspectiva posmodernista, que con el cambio del siglo tenía que preguntarse sobre los valores estéticos, sobre el mismo proceso artístico y sobre su papel en la sociedad contemporánea: la metáfora borgiana del recinto circular de la existencia humana que entreteje los límites de la realidad y de la ficción ha vuelto a un territorio ya conocido.

Los autores españoles e hispanoamericanos, ahora comúnmente, como Enrique Vila-Matas, Javier Cercas, Javier Marías, Rosa Montero, Roberto Bolaño, Leonardo Padura, Ricardo Piglia, Andrés Neuman y muchos más tuvieron que encontrar nuevos caminos, nuevas reflexiones, nuevas voces en la creación novelesca. Y los han ido a buscar en el territorio estético del arte vanguardista, sobre todo preguntándose en sus narraciones sobre su propio arte -la mirada ficcional se ha vuelto metaficcional. Al inicio del siglo XXI la novela española e hispanoamericana ya no trabaja cada una en su lado del Atlántico, sino que a los autores les preocupan las mismas inquietudes existenciales y las mismas reflexiones estéticas.

Al inicio del siglo XXI aparece la autoficción porque de modo vital incluye en el proceso creativo la relación del autor hacia la literatura, hacia la historia y hacia el presente. Todos estos autores sufren de la severa enfermedad de don Quijote, llamada por Onetti la literatosis y expuesta por Bolaño como enfermedad grave. Se trata de la obsesión vital por el mundo de los libros que vuelve a influir sobre las vidas reales de sus autores: 
Llenósele la fantasía de todo aquello que leía en los libros, así de encantamentos como de pendencias, batallas, desafíos, heridas, requiebros, amores, tormentas y disparates imposibles; y asentósele de tal modo en la imaginación que era verdad toda aquella máquina de aquellas soñadas invenciones que leía, que para él no había otra historia más cierta en el mundo (Cervantes, I, I, 2004, 30).

En los relatos autoficcionales autor, narrador y personaje comparten la misma identidad, su conjunto indica que se trata de una novela con límites vagos. Como escribió Franz Kafka en una de sus cartas a su novia Felice Bauer, su personalidad, su ser más íntimo es la literatura misma.

\subsection{Autoficción - AutoRficción}

La frontera entre el mundo real y la ficción se ha derrumbado; al mundo de la ficción entran tanto el autor como el lector, los dos frecuentemete como dos personajes en el texto que discuten sobre el mismo proceso creativo y su propia existencia; la realidad invade la ficción y viceversa sin dejar clara la frontera entre sí. La novela deja de contar solo lo que ocurre en el mundo real o en el interior del alma de los personajes para incluir en la narración también el universo estético artístico y literario como si fuese su parte sustancial. El texto literario ya no tiene sus fundamentos exclusivamente en la realidad exterior o en la realidad interior sino también en la realidad literaria, esto es, en el mundo narrativo. Todas estas realidades forman parte tanto de la vida real como de la ficción, los límites entre ambas se borran, se va formando una estructura cómplice: «la llamada autoficción, que juega con la propia identidad de los materiales narrativos, históricos, biográficos o ensayísticos, hasta borrar con frecuencia su límite» (Pozuelo Yvancos, 2004, 52). Al contrario de la autobiografía, explicativa y unificante, la autoficción no percibe la vida como un todo. Ella no tiene ante sí más que fragmentos disjuntos, pedazos de existencia rotos, un sujeto troceado que no coincide consigo mismo. La autoficción es un relato cuyo autor, narrador y protagonista comparten la misma identidad nominal y cuyo intitulado genérico indica que se trata de una novela. La historia que cuenta tal relato es una historia fragmentada, sus elementos no forman una trama y no tienen una unidad a la que referirse, sino representan una identidad fragmentada.

El origen de la autoficción debemos buscarlo también en la fragmentación y en la deconstrucción del yo autobiográfico de Serge Doubrovsky y de Roland Barthes que lo descomponen en fragmentos discontinuos. Los autores contemporáneos mencionados tanto españoles como hispanoamericanos ${ }^{8}$ recogen los pedazos descompuestos del

8 De conceptos parecidos se sirven también muchos otros escritores contemporáneos europeos, también eslovenos, como por ejemplo Drago Jančar. 
yo y los mezclan de modo irónico literario en voces fantaseadas, ficcionalizadas para marcar la distancia respecto al texto y construir una correlación vital. En estos procesos los autores escriben ficción (frecuentemente con los hechos históricos directamente incluidos) que luego vuelve su impacto vital sobre ellos, pasando por la recepción enigmática y confundidora del lector:

Es una voz que permite construir al yo un lugar discursivo, que le pertenece y no le pertenece al autor, o le pertenece de una forma diferente a la referencial. Le pertenece como voz figurada, es un lugar donde fundamentalmente se despliega la solidaridad de un yo pensante y un yo narrante (Pozuelo Yvancos, 2010, 30).

El lector ve el texto, ve el espejo y no puede distinguir fácilmente cuál de los dos lados es la realidad y cuál la ficción. Se trata del: «dibujo especular de la propia creación en el objeto creado» (Pozuelo Yvancos, 2010, 162). El texto es como un tapiz que se dispara en muchas direcciones, como ha definido en varias ocasiones Enrique Vila-Matas su propia obra, pero que solo en la superficie parece ser fragmentada y dispersa. En su profundidad filosófica, metafísica los autores mencionados de la novela contemporánea intentan encontrar en la crisis contemporánea mediante su propio sistema narrativo -la narración autoficcional- la identidad ontológica, un sistema literario sólido que busque un discurso dialógico con la realidad frágil, instantánea, despedazada. El hombre moderno vive en un oasis de horror, como dice Roberto Bolaño en el epígrafe a su novela 2666, citando a Charles Baudelaire (Bolaño, $2010,9)$. Por eso hay que buscar refugio en la literatura: la realidad se ficcionaliza y la ficción se vuelve real. En su búsqueda al final del posmodernismo muchos narradores de la novela española e hispanoamericana, sin distinción, han regresado hacia los principios vanguardistas. Desde la perspectiva de un sujeto en crisis, desde el yo real/ ficcional intentan dar a la literatura otra vez la coherencia artística al formular un interrogante clave: ¿qué le hace una obra ser arte? La ficción ha vuelto a la esencia estética, propugnada por la vanguardia: el arte tiene que servir al arte, el arte por el arte, l'art pour l'art, larpurlartizem..., pero no encerrado en su torre de marfil sino en un constante vaivén dialógico con la realidad, con el tiempo, con el espacio, entre lo autobiográfico y lo ficcional, en continua hibridez de formas y géneros:

¿Existió realmente Beatriz? La sombra de una ligera sospecha cae sobre ella. Y otra sobre Dante. ¿Acaso tenía recuerdos inventados? Mucho me temo que la autoficción la inventó Dante. «La verdad tiene estructura de ficción», decía Lacan. Y seguro que Dante habría suscrito perfectamente esta frase (VilaMatas, 2005, 26).

La literatura tiene que formar parte vital de la realidad, el relato tiene que ser real, según Javier Cercas, representando a la vez la enfermedad y la salvación, la mentira 
y la verdad, la imaginación y la realidad. Con la vuelta a los principios artísticos vanguardistas los autores rescataron también el pensamiento cervantino sobre la compleja relación entre la realidad y la ficción que revive en numerosas novelas contemporáneas españolas e hispanoamericanas.

\section{Bibliografía}

Bajtin, M., Problemas de la poética de Dostoievski, México 1986.

Barth, J., The Literature of Exhaustion, Atlantic Monthly 220/2, 1967, pp. 29-34.

Bolaño, R., 2666, Barcelona 2010.

Borges, J. L., El Hacedor (Arte poética), Madrid 2002.

Cervantes, M. de, Don Quijote de la Mancha (I, II), Madrid 2004.

Eco, U., Apostillas a El nombre de la rosa, Barcelona 1984.

Fock, I., El fatalismo y la fatalidad a través de la técnica narrativa en la Crónica de una muerte anunciada de Gabriel García Márquez, Verba Hispanica 18/1, 2010, p. 199-212.

Fuguet, A., Gómez, S., McOndo, Barcelona 1996.

Ortega y Gasset, J., Ideas sobre la novela, Madrid 1969.

Ortega y Gasset, J., La deshumanización del arte, Madrid 1987.

Ortega y Gasset, J., Meditaciones del Quijote, Madrid 2004.

Pozuelo Yvancos, J. M., Ventanas de la ficción. Narrativa hispánica siglos XX y XXI, Barcelona 2004.

Pozuelo Yvancos, J. M., Figuraciones del yo en la narrativa, Valladolid 2010.

Šabec, M., El mito y la mirada, Ars \& Humanitas IX/1, 2015, pp. 9-13.

Unamuno, M. de, Niebla, Madrid 1995.

Vila-Matas, E., El Mal de Montano, Barcelona 2002.

Vila-Matas, E., Autoficción, Quimera 263-264, 2005.

Yvancos, J. M., Figuraciones del yo en la narrativa, Valladolid 2010. 


\section{Branka Kalenić Ramšak \\ Večni avantgardizem: dialoški princip $v$ španskem in hispanoameriškem romanu}

Ključne besede: avantgarda, polifonični roman, avtofikcija, španski in hispanoameriški pripovedovalci

Teoretski okvir članka je osnovan na teoriji Mihaila Bahtina, ki je opredelil prehod $\mathrm{z}$ realističnega na avantgardni roman: prej monološki roman se je namreč spremenil v polifoničnega. Kako pa je takšna sprememba vplivala na španske in hispanoameriške pripovedovalce? Ti so se znova začeli ozirati $\mathrm{k}$ Cervantesu. Članek skuša skozi obravnavo postmodernističnih pripovednih principov opredeliti sodobne tendence avtofikcije ter pri tem navaja nekatere španske in hispanoameriške avtorje, ki v ospredje ponovno postavljajo Cervantesova razmišljanja in obujajo avantgardna estetska načela, pri čemer se posvečajo predvsem kompleksnemu odnosu med resničnostjo in fikcijo ter njunim medsebojnim vplivom. 


\section{Branka Kalenić Ramšak}

\section{The eternal avant-garde: the dialogical principle in the Spanish and Spanish-American novel}

Keywords: avant-garde, polyphonic novel, autofiction, Spanish and SpanishAmerican narrators

The article is based on the theory of Mikhail Bakhtin that determined the change of the realist novel in the development of the avant-garde novel, in which the novel ceased to be monological and became instead polyphonic. What consequences did such a change have on the Spanish and Spanish-American narrators? They looked again at Cervantes. Going through the postmodern narrative principles the article tries to define the current trends of autofiction with mention of some Spanish and Spanish-American authors who again highlight the influence of Cervantes and revive the aesthetic principles of the avant-garde, with a focus on the complex relationships between reality and fiction and their mutual influence. 